\title{
Preparation, characterization, and evaluation of polymeric resin (BHMET) from the reaction of malic anhydride with recycled PET as a corrosion inhibitor for $\mathrm{C}$ - steel in $\mathrm{HCl}$
}

Preparación, caracterización y evaluación de resina polimérica (AHMET) a partir de la reacción de anhídrido maleico con PET reciclado como inhibidor de corrosión para acero-C en $\mathrm{HCl}$

Author:

Yasir $\mathbf{A}^{1}$

Khalaf $\mathbf{A}^{2}$

Khalaf $\mathbf{M}^{3}$

\section{SCIENTIFIC RESEARCH}

How to cite this paper:

Yasir A, Khalaf A and Khalaf M . Preparation, characterization and evaluation of polymeric resin (BHMET) from reaction of malic anhydride with recycled PET as a corrosion inhibitor for $\mathrm{C}$ - steel in $\mathrm{HCl}$ Innovaciencia. 2019;7 (1): 1-12.

http://dx.doi.org/10.15649/2346075X.510

Reception date:

Received: 20 February 2019

Accepted: 29 April 2019

Published: 25 October 2019

Keywords:

Waste polymer, Glycolysis, Corrosion inhibitor

\section{ABSTRACT}

Introduction: The plastic soft drink bottle from polyethylene terephthalate (PET) was introduced to consumers in 1970s. Because PET have ester group its chemical recycling is preferred. To control and reduce the environmental pollution recycling and reusing of PET has turned into an imperative procedure from the ecological perspective and it has given business opportunity because of far reaching use and accessibility of PET polymer. Also another source of pollution to the environment was the corrosion of materials. Corrosion is the deterioration and loss of a material and its critical properties due to chemical, electrochemical and other reactions of the exposed material surface with the surrounding environment. Understanding corrosion mechanisms allow to use corrosion-resistant materials and altering designs. Organic inhibitors are very efficient to protect the metals from corrosion in all chemicals (acidic, basic and salt) media. There were many types of corrosion inhibitors and the organic inhibitor are being applied widely to protect metals from corrosion in many aggressive media. The aim of this study is to utilize waste PET-bottles will be depolarized by 2,2-dithioethanol to produce (Bis(2-((2-hydroxyethyl) thio) ethyl) terephthalate (BHTE), then by reacting of (BHTE) with maleic anhydride to produce Bis (2-((6-Mono malic acid -hydroxyethyl ester) sulfanyl) ethyl terephthalate(BHMET). The prepared (BHMET) will be used as corrosion inhibitor and its efficiency to protect the carbon steel in acidic will be assessed. Materials and Methods: Depolymerization of PET waste done with 2,2-dithioethanol. The weight proportion of PET to 2,2-dithioethanol 1:8 (wt $\%)$ and zinc acetate $(0.5 \mathrm{wt} \%$ based on PET) was added as catalyst. Temperature of the reaction mixture was between $160-180{ }^{\circ} \mathrm{C}$ for $12 \mathrm{~h}$, then the reaction mixture was kept at $140{ }^{\circ} \mathrm{C}$ for $3 \mathrm{~h}$, then allowed to cool to room temperature. With vigorous agitation distilled water in excess to the reaction mixture to allow the black liquid viscous compound oligomer of Bis(2-((2-hydroxyethyl) thio) ethyl terephthalate (BHET) to precipitate. In a three neck round bottom $(250 \mathrm{ml})$ attached with mechanical stirrer and thermometer $(5.7 \mathrm{gm})$ of (BHET) compound was added and heated for $(15 \mathrm{~min}$.$) at \left(60^{\circ} \mathrm{C}\right)$. Then $(2.5 \mathrm{gm})$ of malic anhydride and $(1 \%)$ sulfuric acid was added. By the mechanical stirrer the mixture was mixed for $\left(50 \mathrm{~min}\right.$.) at temperature $\left(80^{\circ} \mathrm{C}\right)$. After the reaction the mixture was washed with distilled water to avoid the acid residue. Scheme (1) shows the mechanism for the prepared (BHMET) corrosion inhibitor.

Ministry of Oil, Basrah Oil Company, Basrah-Iraq.

Department, of chemistry, College of Science, University of Basrah, Basrah-Iraq.

Department of Chemistry, College of Science, University of Basrah, Basrah, Iraq. email: moayad_khalaf@yahoo.com 
Results and Discussion: Polarization Tafel plot in presence and absence of different concentrations of BHMET show that the Tafel factors, inhibition efficiency ( $\%$ IE), surface coverage $(\theta)$, corrosion rate and charge transfer resistance was measure. It is apparently that the shapes of the Tafel plots for the inhibited and uninhibited carbon steel are different. The current density of the inhibited carbon steel decreases, while the other parameters behavior does not change. A negative shift was observed for the corrosion potential $\left(\mathrm{E}_{\text {corr }}\right)$ due to adsorption of the inhibitor. Tafel slopes ( $(\mathrm{a}$ and $ß \mathrm{c}$ ), the anodic and catholic both decreases with the addition of BHMET. This reveals that BHMET is a mixed-type inhibitor influencing the iron dissolution and hydrogen evolution. The decrease of the positive and negative currents in the with using the corrosion inhibitor BHMET due to passivation the active sites on the surface of the electrode. At inhibitor (BHMTE) concentration of 50PPM at 298k the surface coverage and inhibition efficiency reached its maximum. Conclusions: Bis [2\{(6-Mono malic acid -hydroxyethyl ester\}sulfanyl]ethyl terephthalate (BHMET) prepared and used as corrosion inhibitors of carbon steel in $0.1 \mathrm{M} \mathrm{HCl}$ solution. Two parameters effects were studied, The concentration of the inhibitor (BHMET) and the temperature. From the data, the higher (\%IE) was for the $10 \mathrm{ppm}$ at 298 and at 313 the 10ppm was the higher inhibitor efficiency. The adsorption of the BHMET inhibitor onto the surface of the carbon steel follows the Langmuir's adsorption isotherm. The prepared compound was mixed type inhibitor and the $\Delta \mathrm{G}^{\circ}$ ads indicates that the adsorption of (BHMET) inhibitor involves chemisorption.

\section{INTRODUCTION}

The plastic soft drink bottle from polyethylene terephthalate (PET) was introduced to consumers

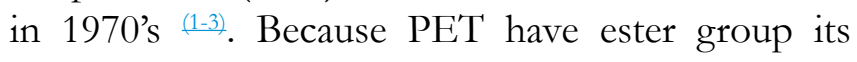
chemical recycling is preferred. To control and reduce the environmental pollution recycling and reusing of PET has turned into an imperative procedure from the ecological perspective and it has given business opportunity because of far reaching use and accessibility of PET polymer ${ }^{(4-7)}$. Also another source of pollution to the environment was the corrosion of materials ${ }^{(8)}$. Corrosion is the deterioration and loss of a material and its critical properties due to chemical, electrochemical and other reactions of the exposed material surface with the surrounding environment $\frac{(9-11)}{\text {. Understanding }}$ corrosion mechanisms allow to use corrosion-

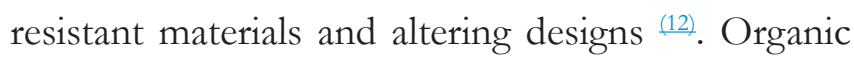
inhibitors are very efficient to protect the metals from corrosion in all chemicals (acidic, basic and salt) media. There are many types of corrosion inhibitors and the organic inhibitor being applied widely to protect metals from corrosion in many aggressive media. The aim of this study is to utilize waste PET-bottles will be depolarized by 2,2-dithioethanol to produce (Bis(2-((2-hydroxyethyl) thio) ethyl) terephthalate (BHTE), then by reacting of (BHTE) with maleic anhydride to produce Bis (2-((6-Mono malic acid -hydroxyethyl ester)sulfanyl) ethyl terephthalate(BHMET).The prepared (BHMET) will be used as corrosion inhibitor and its efficiency to protect the carbon steel in acidic will be assessed .

\section{MATERIALS AND METHODS}

\section{Materials}

Carbon steel (C1010) obtained from Metal Samples (USA) its composition was: $\mathrm{C}=0.13, \mathrm{Mn}=0.3$, $\mathrm{Si}=0.37, \mathrm{P}=0.04, \mathrm{~S}=0.05, \mathrm{Cr}=0.1, \mathrm{Ni}=0.3, \mathrm{Cu}=0.3$, $\mathrm{AS}=0.08$ and the reminder was Fe. PET waste bottle was collected and grinded. 2,2-dithioethanol, Zinc acetate, malic anhydride and $\mathrm{HCl}$ were obtained from Aldrich Chemical Co.

\section{Instruments}

Fourier transforminfrared (FT-IR) spectroscopic measurements were made using Jasco 4200 spectrometer. NMR spectra was obtained by Bruker -400 MHZ using DMSO as solvent while the thermal analysis was measured using TGA-DTA from Netzsch (STA 449).

\section{Corrosion Inhibition Measurements}

The corrosion inhibition measurements were performed utilizing a potentiostat/ galvanostat DY2300 Series Potentiostat/Bipotentiostat supplied by Digi-lvy company. A three electrode cell gathering, comprising of a platinum as the counter electrode (CE), a saturated calomel electrode as the reference electrode (RE) and C-steel rod as the working electrode (WE). A water bath was used to maintain the temperature at the required temperature of the 
electrolyte. From the polarization data, the following parameters were achieved the degree of surface coverage $(\theta)$, the percentage inhibition efficiency $(\%$ IE), corrosion rate and charge transfer resistance. $\frac{(13)}{}$

\section{Chemical recycling of PET}

Depolymerization of PET waste done with 2,2-dithioethanol. The weight proportion of PET to 2,2-dithioethanol 1:8 (wt \%) and zinc acetate (0.5 wt $\%$ based on PET) was added as catalyst. Temperature of the reaction mixture was between 160-180 ${ }^{\circ} \mathrm{C}$ for $12 \mathrm{~h}$, then the reaction mixture was kept at $140{ }^{\circ} \mathrm{C}$ for $3 \mathrm{~h}$, then allowed to cool to room temperature. With vigorous agitation distilled water in excess to the reaction mixture to allow the black liquid viscous compound oligomer of $\mathrm{Bis}\left(2-\left(\mathrm{C}^{-}\right.\right.$ hydroxyethyl) thio)ethyl terephthalate (BHET) to precipitate $\frac{(14)}{}$. In a three neck round bottom $(250 \mathrm{ml})$ attached with mechanical stirrer and thermometer $(5.7 \mathrm{gm})$ of (BHET) compound was added and heated for $(15 \mathrm{~min}$.$) at \left(60^{\circ} \mathrm{C}\right)$. Then $(2.5 \mathrm{gm})$ of malic anhydride and (1\%) sulfuric acid was added. By the mechanical stirrer the mixture was mixed for $\left(50 \mathrm{~min}\right.$.) at temperature $\left(80^{\circ} \mathrm{C}\right)$. After the reaction the mixture was washed with distilled water to avoid the acid residue. Scheme (1) shows the mechanism for the prepared (BHMET) corrosion inhibitor.
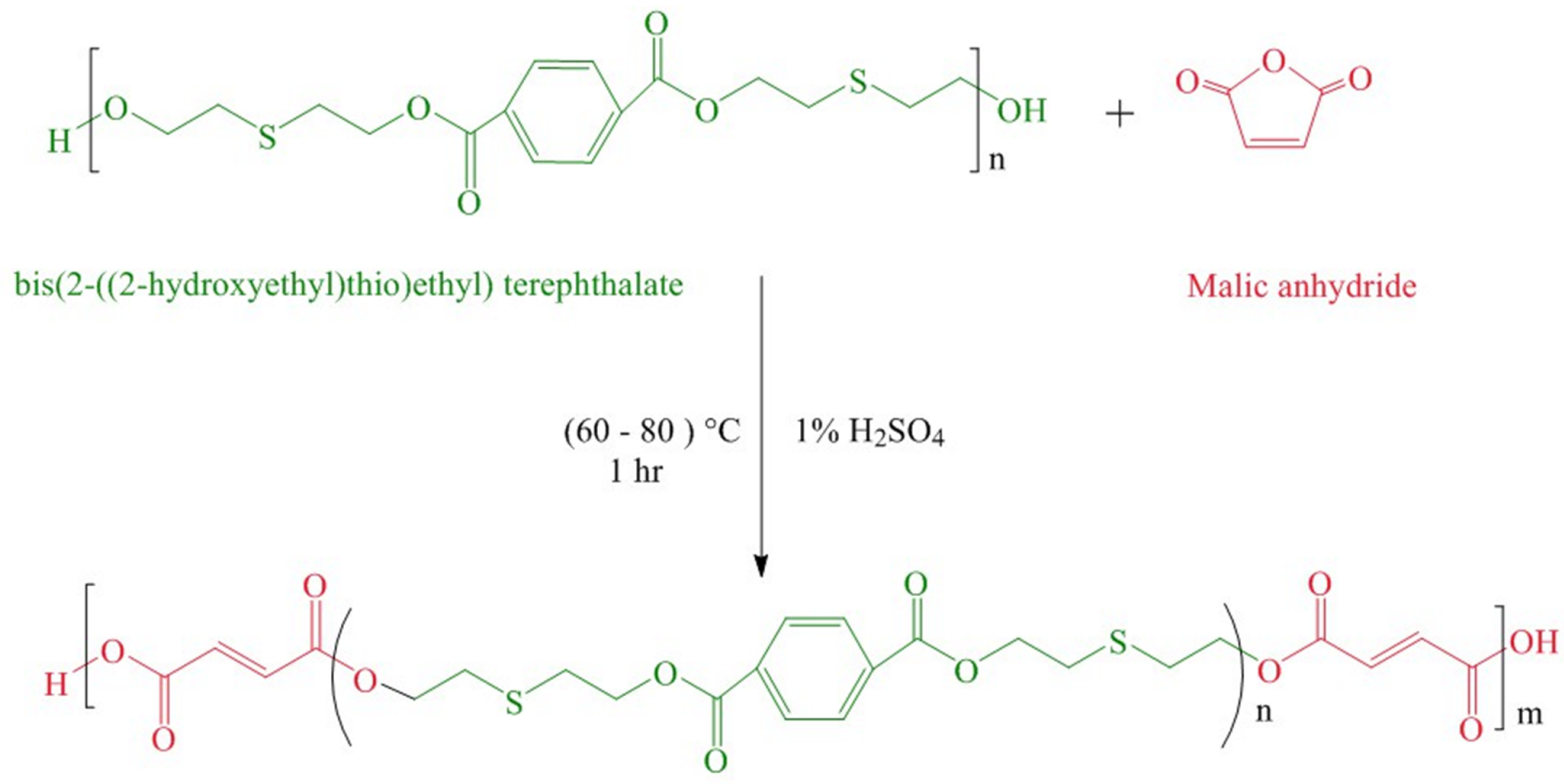

Bis $\{2-(6$ - mono malic acid - ethyl ester) sulfanyl $\}$ ethyl terphthalate

Scheme (1). Mechanism of BHMET preparation

\section{Characterization for inhibitor}

The FTIR spectrum of the corrosion inhibitor (BHMET) is presented in Fig. 1. Fig.1 shows the band at (1717) $\mathrm{cm}^{-1}$ which is assigned for the ester carbonyl group, while the strong band at $\left(3416 \mathrm{~cm}^{-1}\right)$ assigned to carboxyl group $(\mathrm{COOH})$. A weak aliphatic band at $\left(1641 \mathrm{~cm}^{-1}\right)$ assigned to $(\mathrm{C}=\mathrm{C})$ and $(\mathrm{C}-\mathrm{S})$ band appear at $\left(1050 \mathrm{~cm}^{-1}\right)$ and the band at $\left(1221 \mathrm{~cm}^{-1}\right)$ is attributed to stretching vibrations $\mathrm{C}-\mathrm{O}$ in the cyclic anhydride (15). The ${ }^{1}$ HNMR of the (BHMET) is shown in Fig. 2. From the Figure the singlet weak wide peak (a) at (13.15ppm) was attributed to the terminated proton of the carboxyl group $(-\mathrm{COOH})$ and another strong multiples (b) at $(8.17 \mathrm{ppm})$ is assigned to the proton of the benzene group and a doublet peak (c) at $(6.47 \mathrm{ppm})$ is attributed to the proton of the double bond. A triplet peak(d) is attributed to the methylene group next to the carbonyl ester at (4.54 ppm) due to the proton which is affected by the nearest proton of the $\left(\mathrm{CH}_{2}\right)$.

A strong triplet peak (e) at $(4.31 \mathrm{ppm})$ is attributed to the methylene group near the oxygen atom. Strong triplet peak (f) at (3.62) was assigned to the symmetric methylene groups near the sulfur atom and a (g) 
peak appeared at $(3.01 \mathrm{ppm})$ for the asymmetric methylene groups near the sulfur group. While the strong multiple $(\mathrm{h})$ at $(2.59 \mathrm{ppm})$ is attributed to the used solvent ${ }^{\mathrm{d} 6}$-DMSO $\stackrel{(16-18)}{ }$.

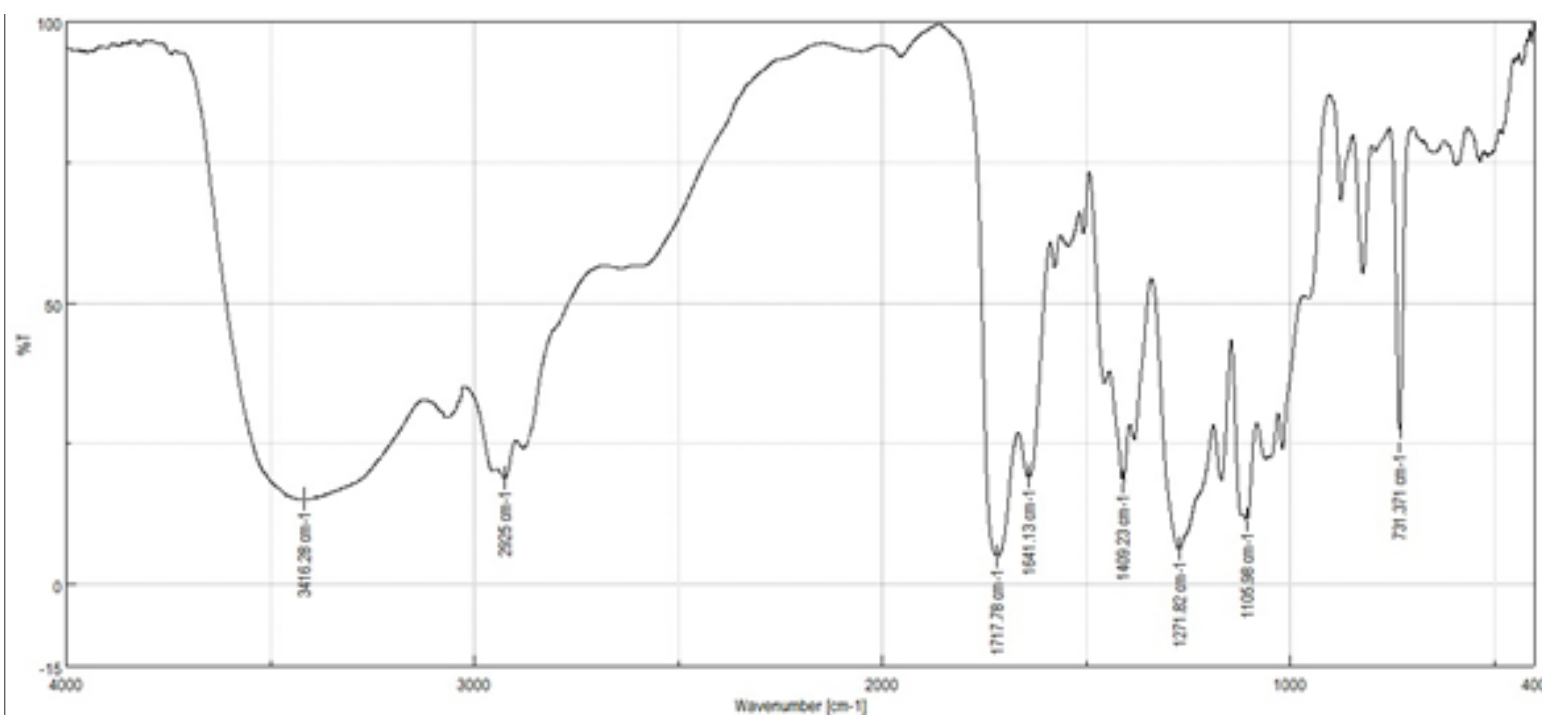

Figure 1. FTIR spectra of BHMET

\section{RESULTS AND DISCUSSION}

\section{Electrochemical Measurements}

\section{Polarization Measurements (Tafel method)}

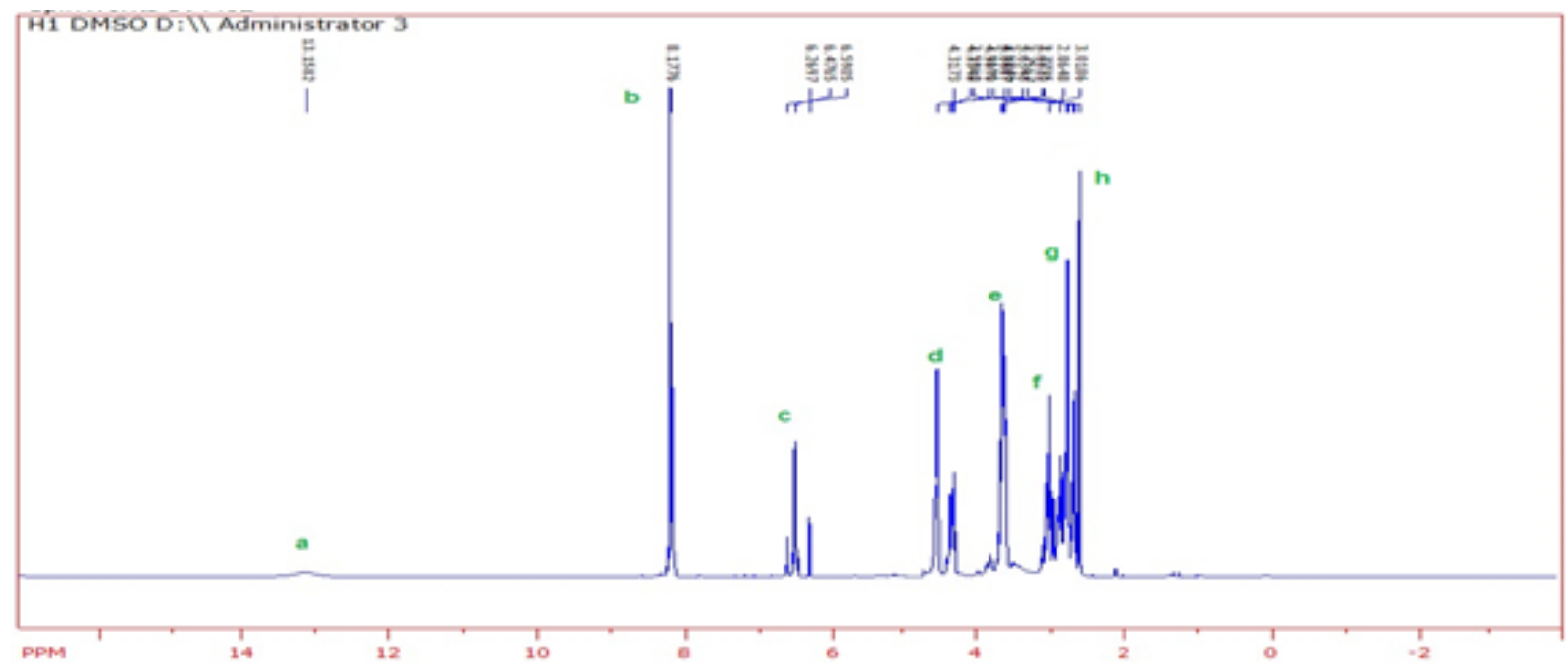

Figure 2. HNMR spectra of BHMET. $a=13.15 \mathrm{ppm}, \mathrm{b}=8.17 \mathrm{ppm}, \mathrm{c}=6.47 \mathrm{ppm}, \mathrm{d}=4.54 \mathrm{ppm}, \mathrm{e}=4.31 \mathrm{ppm}$, $\mathrm{f}=3.62, \mathrm{~g}=3.01 \mathrm{ppm}, \mathrm{h}=2.59 \mathrm{ppm}$.

Polarization Tafel plot in presence and absence of different concentrations of BHMET are shown in Figs. (3-6). The Tafel factors, inhibition efficiency $(\% \mathrm{IE})$, surface coverage $(\theta)$, corrosion rate and charge transfer resistance was given in Table 1. It is apparently that the shapes of the Tafel plots for the inhibited and uninhibited carbon steel are different. The current density of the inhibited carbon steel decreases, while the other parameters behavior does not change. A negative shift was observed for the corrosion potential $\left(\mathrm{E}_{\text {corr }}\right)$ due to adsorption of 
the inhibitor. Tafel slopes ( $\mathrm{a} \mathrm{a}$ and $\mathrm{Bc}$ ), the anodic and catholic both decreases with the addition of BHMET. This reveals that BHMET is a mixed-type inhibitor influencing the iron dissolution and hydrogen evolution $\frac{(19,20)}{}$. The decrease of the positive and negative currents in the with using the corrosion inhibitor BHMET due to passivation the active sites on the surface of the electrode ${ }^{(21,22)}$. At inhibitor (BHMTE) concentration of 50PPM at 298k the surface coverage and inhibition efficiency reached its maximum. As can be seen from Table 1, BHMET inhibitor greatly reduce corrosion current with a slight shift in the corrosion potential.
Table (1) shows the values of (Rct) increases with inhibitor concentration, which indicates that the efficiency inhibitor to preventing the corrosion of carbon - steel and indicating that the amount of inhibitor adsorbs on the surface of the carbon-steel increasing. The highest resistance to charge transfer $\left(\mathrm{R}_{\text {ct(inh.) }}\right)$ value at $(298 \mathrm{~K})$ was $(497.1 \Omega)$ at concentration $(50 \mathrm{ppm})$ of the inhibitor BHMET at $(328 \mathrm{~K})$, while for the uninhibited was $(18.69 \Omega)$ at the same temperature $\stackrel{(23)}{\longrightarrow}$

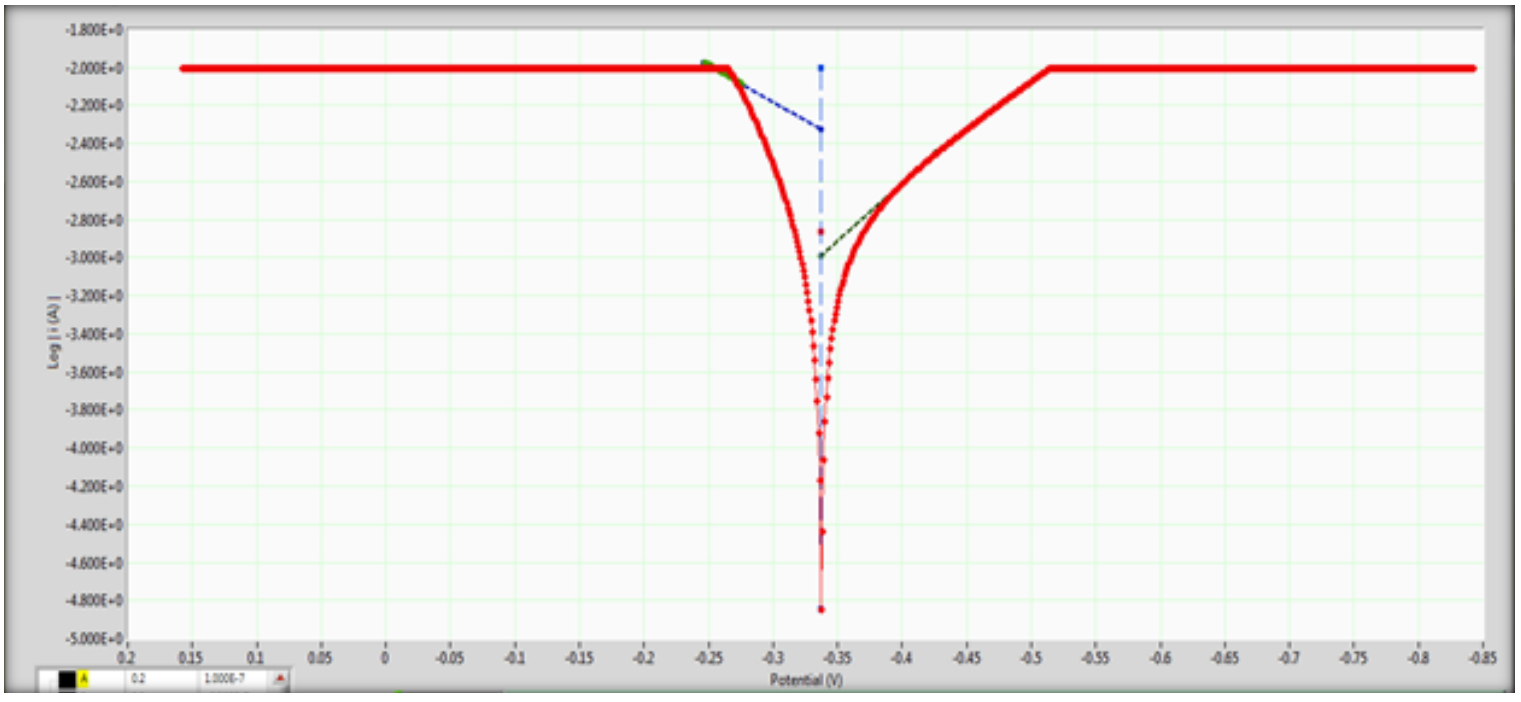

Figure 3. Potentiodynamic polarization curves for carbon steel corrosion in $0.1 \mathrm{M} \mathrm{HCl} \mathrm{303K(blank)}$

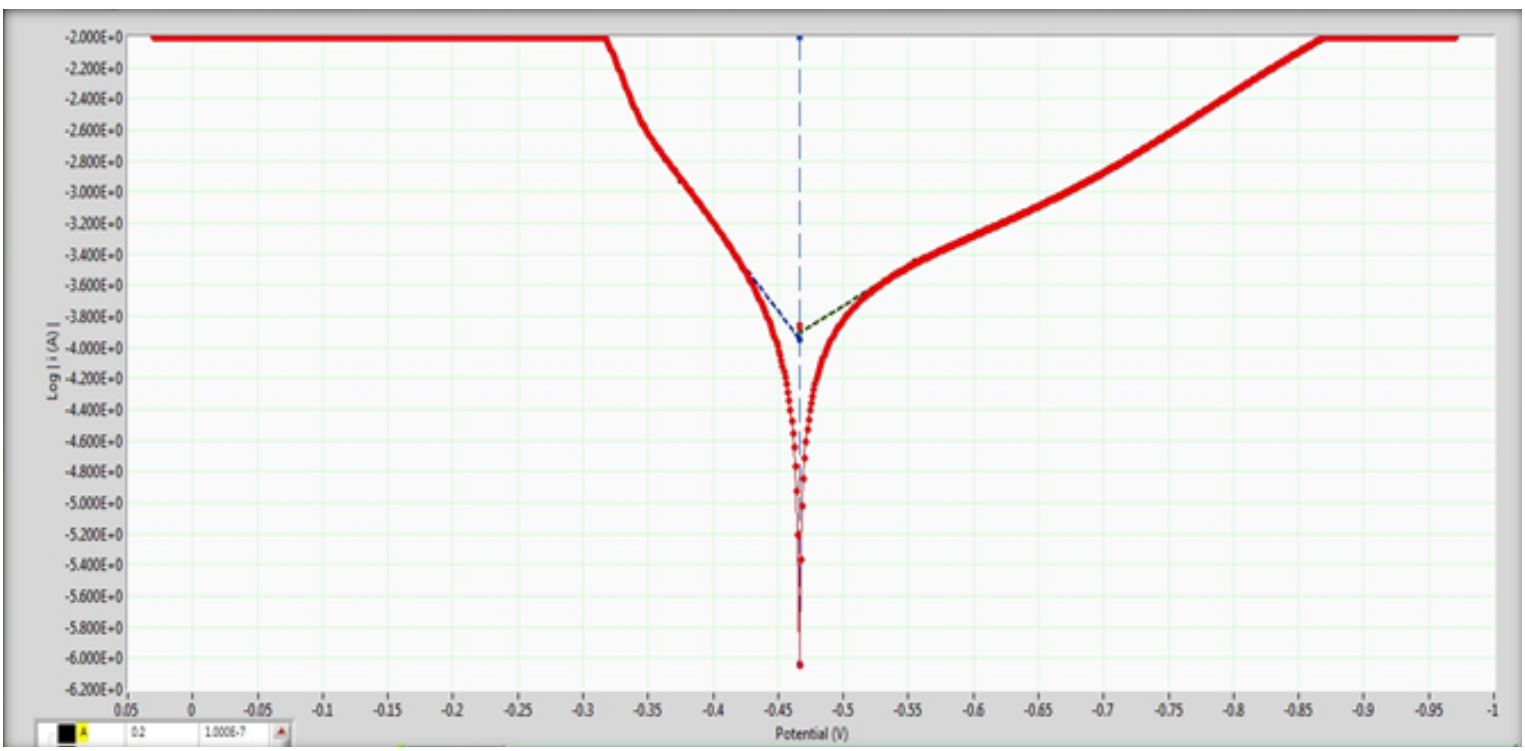

Figure 4. Potentiodynamic polarization curves for carbon steel corrosion in $0.1 \mathrm{M} \mathrm{HCl}$ in presence of 50ppm BHMET at 303K. 


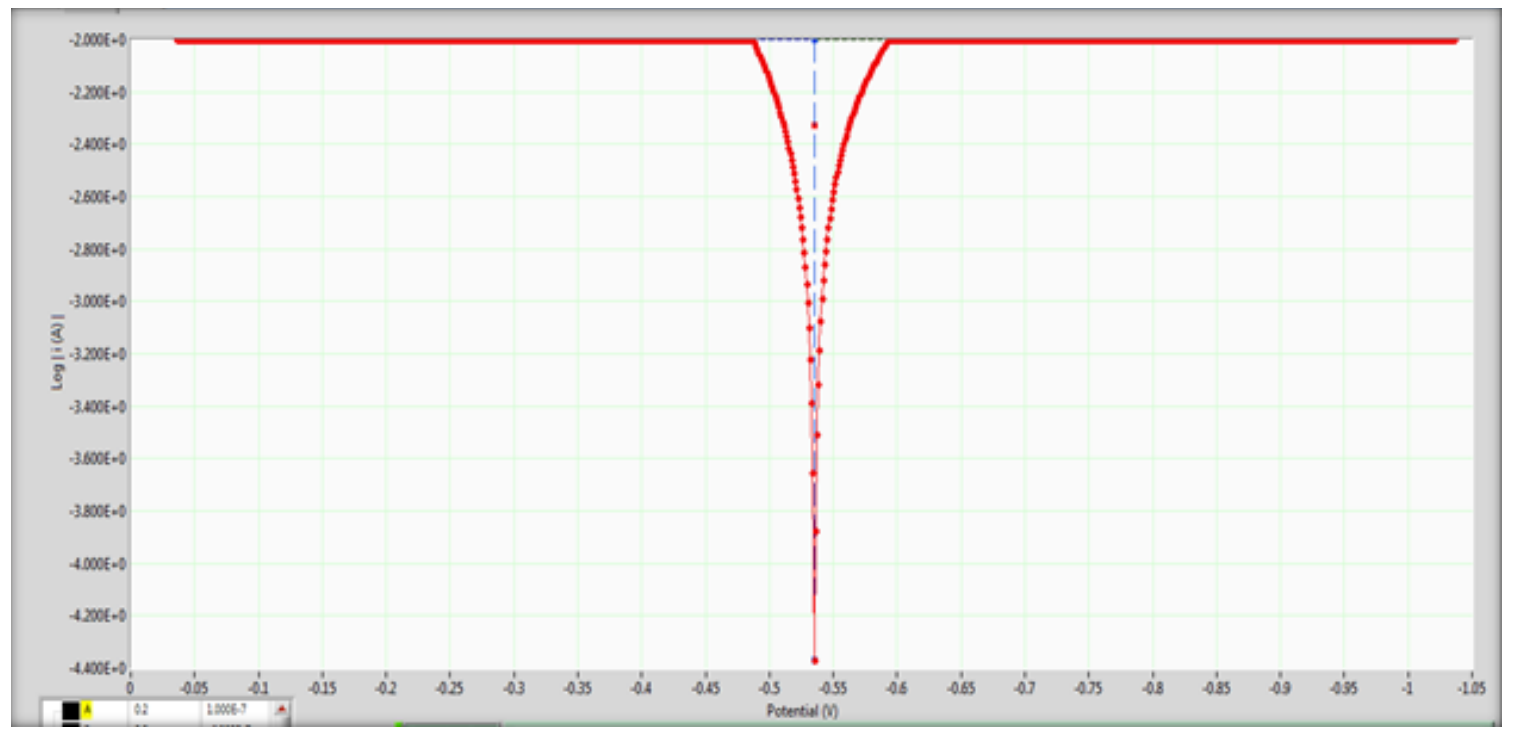

Figure 5. Potentiodynamic polarization curves for carbon steel corrosion in $0.1 \mathrm{M} \mathrm{HCl}$ at $333 \mathrm{~K}$ (blank)

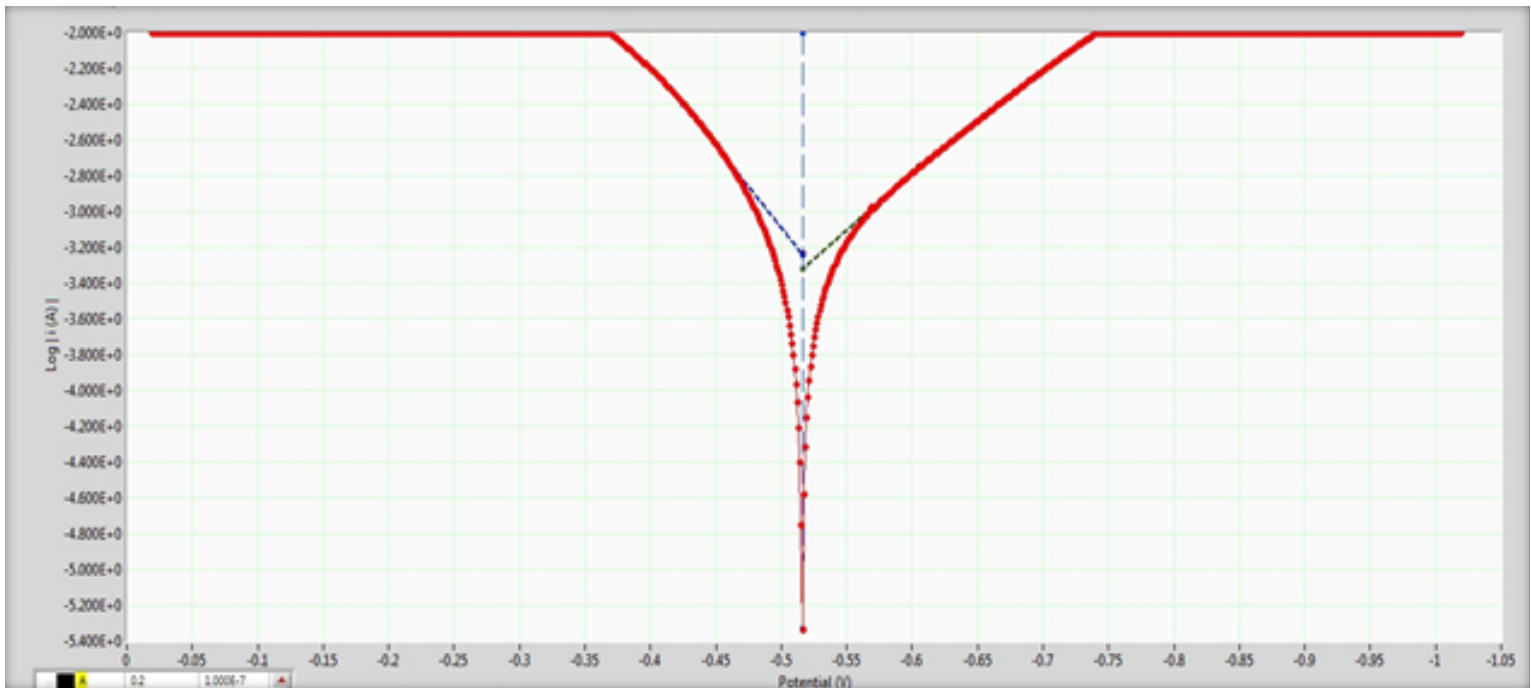

Figure 6. Potentiodynamic polarization curves for carbon steel corrosion in $0.1 \mathrm{M} \mathrm{HCl}$ in presence of 10 ppm BHMET at $333 \mathrm{~K}$ 
Table 1. The effect of inhibitor(BHMET) concentrations at different temperatures on the Tafel parameters for C-steel in $0.1 \mathrm{M} \mathrm{HCl}$

\begin{tabular}{|c|c|c|c|c|c|c|c|c|c|}
\hline $\begin{array}{c}\text { Conc. } \\
\text { ppm }\end{array}$ & $\begin{array}{l}\text { T. } \\
\mathbf{K}\end{array}$ & $\begin{array}{c}\text { Ecorr } \\
\text { mv }\end{array}$ & $\begin{array}{c}\beta \mathrm{a} \\
\mathrm{A} / \mathrm{V}\end{array}$ & $\begin{array}{c}\mathrm{Bc} \\
\mathrm{A} / \mathrm{V}\end{array}$ & $\begin{array}{c}\text { Icorr } \\
\mathrm{mA} / \mathrm{cm}^{2}\end{array}$ & $\begin{array}{c}\text { Rct } \\
\Omega\end{array}$ & $\begin{array}{l}\text { CR } \\
\text { mpy }\end{array}$ & $\% \mathrm{IE}$ & 凶 \\
\hline Blank & \multirow{6}{*}{298} & -517 & 3.934 & -6.073 & 1.375 & 18.69 & 74.3 & - & - \\
\hline 10 & & -482 & 11.23 & -6.080 & $6.510 \times 10^{-2}$ & 394.7 & 3.51 & 95.2 & 0.952 \\
\hline 20 & & -479 & 10.85 & -6.072 & $5.789 \times 10-2$ & 443.9 & 3.12 & 95.7 & 0.957 \\
\hline 30 & & -482 & 10.88 & -6.162 & $5.745 \times 10-2$ & 447.2 & 3.10 & 95.8 & 0.958 \\
\hline 40 & & -486 & 9.155 & -6.322 & $5.287 \times 10-2$ & 485.9 & 2.85 & 96.1 & 0.961 \\
\hline 50 & & -483 & 9.207 & -6.199 & $5.168 \times 10-2$ & 497.1 & 2.79 & 96.2 & 0.962 \\
\hline Blank & \multirow{5}{*}{308} & -523 & 4.574 & -5.954 & 2.117 & 12.14 & 114.41 & - & - \\
\hline 10 & & -470 & 1.150 & -5.247 & $1.481 \times 10-1$ & 173.5 & 8.0 & 93.0 & 0.930 \\
\hline 20 & & -466 & 12.64 & -4.934 & $1.538 \times 10^{-1}$ & 167.1 & 8.31 & 92.7 & 0.927 \\
\hline 30 & & -474 & 11.49 & -5.245 & $2.088 \times 10-1$ & 123 & 11.28 & 90.1 & 0.901 \\
\hline 40 & & -475 & 10.95 & -5.203 & $1.798 \times 10-1$ & 142.9 & 9.71 & 91.5 & 0.915 \\
\hline 50 & & -466 & 11.4 & -5.134 & $1.380 \times 10-1$ & 186.1 & 7.46 & 93.5 & 0.935 \\
\hline Blank & \multirow{6}{*}{318} & -527 & 8.233 & -5.606 & 3.344 & 7.684 & 180.72 & - & - \\
\hline 10 & & -367 & 10.29 & -6.104 & $3.783 \times 10-1$ & 67.91 & 20.44 & 88.6 & 0.886 \\
\hline 20 & & -509 & 10.43 & -6.313 & $4.421 \times 10-1$ & 58.12 & 23.89 & 86.7 & 0.867 \\
\hline 30 & & -371 & 10.43 & -5.649 & $3.850 \times 10-1$ & 66.74 & 20.81 & 88.4 & 0.884 \\
\hline 40 & & -392 & 9.558 & -6.938 & $6.40 \times 10-1$ & 40.15 & 34.58 & 80.8 & 0.808 \\
\hline 50 & & -384 & 9.760 & -6.776 & $5.280 \times 10-1$ & 49.34 & 28.14 & 84.4 & 0.844 \\
\hline Blank & \multirow{6}{*}{328} & -535 & 8.233 & -5.668 & 4.709 & 5.456 & 254.52 & - & - \\
\hline 10 & & -516 & 9.370 & -6.458 & $5.816 \times 10-1$ & 44.18 & 31.43 & 87.6 & 0.876 \\
\hline 20 & & -391 & 8.857 & -7.475 & $8.249 \times 10-1$ & 31.15 & 44.6 & 82.4 & 0.824 \\
\hline 30 & & -401 & 9.075 & -7.168 & $8.420 \times 10-1$ & 30.51 & 45.5 & 82.1 & 0.821 \\
\hline 40 & & -387 & 9.025 & -7.460 & $7.790 \times 10-1$ & 32.98 & 42.11 & 83.4 & 0.834 \\
\hline 50 & & -389 & 9.492 & -6.697 & $7.317 \times 10-1$ & 35.12 & 39.55 & 84.4 & 0.844 \\
\hline
\end{tabular}

\section{Effect of Temperature}

Temperature was highly affected by the action of inhibitor. The reaction between the acid media and the metal was affected by the temperature. In the acidic media the corrosion rate increase with increase temperature due to decreases of hydrogen evolution (24,25). Table 1 shows the decrease of the efficiency of the (BHMET) inhibitor with increasing temperature from(298-328K) via the decreasing of the corrosion rate $\mathrm{C}$-steel in $0.1 \mathrm{M} \mathrm{HCl}$, the inhibitor efficiency $(\%$ IE) decreased from $96.2 \%$ at $308 \mathrm{~K}$ to $84.4 \%$ at $328 \mathrm{~K}$ for $50 \mathrm{ppm}$ concentration of (BHMET) inhibitor. Arrhenius equation used to calculate the activation energy Ea of the corrosion process in $0.1 \mathrm{M} \mathrm{HCl}$ in the presence and absence of inhibitor (BHMET): ${ }^{(26)}$

$$
\ln \mathrm{W}=\ln A-\frac{\mathrm{Ea}}{\mathrm{RT}}
$$

Where Ea is the activation energy, $\mathrm{A}$ is the Arrhenius constant, $\mathrm{W}$ is the corrosion rate (mpy), $\mathrm{R}$ is the gas constant and $\mathrm{T}$ is the absolute temperature, and equation 2

$$
\ln \frac{W}{\mathrm{~T}}=\ln \frac{\mathrm{R}}{\mathrm{Nh}}+\frac{\Delta \mathrm{S}}{\mathrm{R}}-\frac{\Delta \mathrm{H}}{\mathrm{RT}}
$$

Where N, h was Avogadro number and Plank constant.

From Fig. 12 the straight lines was obtained and from equations $(1,2)$ values of $\mathrm{Ea}$ found to be 0.0337 $\mathrm{kJ} \cdot \mathrm{mol}^{-1}$ and $0.0619 \mathrm{~kJ} \cdot \mathrm{mol}^{-1}$ in the absence and pres- 
ence of $50 \mathrm{ppm}$ of inhibitor (BHMET), respectively. Results of Ea indicates a strong inhibition action which increase the energy barrier for the corrosion process in the presence of inhibitor (BHMET) than the situation without inhibitor $\frac{(27)}{2}$.

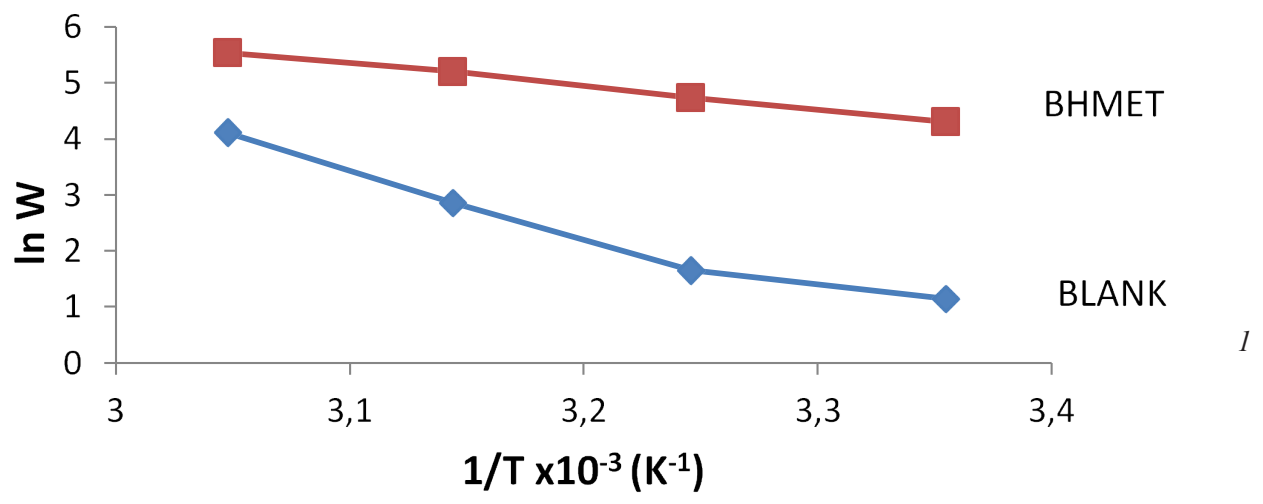

Figure 7. Plot of lnw and 1/t for the blank and $50 \mathrm{ppm}$ (BHMET) inhibitor

And other parameters were calculated from Fig.7 using equation 2 the enthalpies $(\Delta \mathrm{H})$, which had positive sign indicates that its endothermic nature of

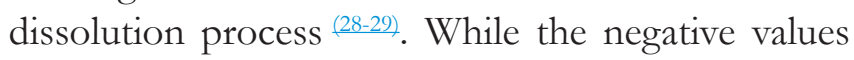
of entropies $(\Delta \mathrm{S})$ show that the activated complex in the rate determining step represents an association rather than a dissociation step, meaning that a decrease in disordering takes place on going from reactants to the activated complex.

Table 3. Thermodynamic parameters for mild steel in $0.1 \mathrm{M} \mathrm{HCl}$ in absence and presence of $50 \mathrm{ppm} \mathrm{BH-}$ MET.

\begin{tabular}{cccc}
\hline Inhibitor con.(ppm) & Ea (kJmol-1) & $\boldsymbol{\Delta H}$ (kJmol-1) & $\boldsymbol{\Delta S}$ (KJmol-1 K-1) \\
\hline 0 (BLANK) & 0.0337 & 0.0705 & -0.19685 \\
30 & 0.0706 & 0.2088 & -0.19646 \\
\hline
\end{tabular}

\section{Adsorption isotherm}

Adsorption isotherms related to the mechanism of inhibition corrosion reactions. The adsorption isotherm depends on the chemical structures of the inhibitor, and the electrochemical processes on the metal surface related to the adsorption of the inhib-

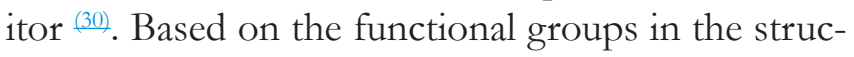
ture of the inhibitor the adsorption of the inhibitor molecules on the surface of the metal. The degree of surface coverage $(\theta)(\theta=\mathrm{E}(\%) / 100)$ and the $\mathrm{K}_{\text {ads }}$ was calculated using (eq. 4).

$$
\theta=\mathrm{E}(\%) / 100
$$

$$
\mathbf{K}_{\mathrm{ads}}=\frac{\theta}{(\mathbf{1}-\boldsymbol{\theta}) \mathrm{C}}
$$

Where $\mathrm{C}$ is the concentration of inhibitor, $\mathrm{K}_{\text {ads }}$ the adsorptive equilibrium constant, and $\theta$ is the fraction of the surface covered. While the standard free energy of adsorption reaction $\left(\Delta G_{\text {ads }}^{0}\right)$ related to the $\left(\mathrm{K}_{\mathrm{ad}}\right)$ shown by following equation ${ }^{(34)}$ :

$$
\Delta \mathrm{G}_{\mathrm{ads}}^{0}=-\mathrm{R} \mathrm{T} \ln 55.5 \mathrm{~K}_{\mathrm{ad}}
$$

$\mathrm{K}_{\text {ads }}$ the adsorptive equilibrium constant, $\mathrm{T}$ is the absolute temperature $(K), R$ is the universal gas constant and the value of 55.5 is the concentration of water in the solution in $\mathrm{mol} / \mathrm{L}$ and the data shown in table (4). 
Table 4. The adsorption free energy $\left(\Delta \mathrm{G}^{\circ}{ }_{\mathrm{ad}}\right)$ and equilibrium constant $\left(\mathrm{K}_{\mathrm{ad}}\right)$, for the adsorption of inhibitors on C-steel in $0.1 \mathrm{M} \mathrm{HCl}$ at (298 k).

\begin{tabular}{|c|c|c|c|c|}
\hline $\begin{array}{c}\text { Conc. } \\
\text { ppm }\end{array}$ & T. $\mathrm{k}$ & $\theta$ & $\begin{array}{l}\Delta \mathrm{G} 0 \mathrm{ads} \\
(\mathrm{KJ} / \mathrm{mol})\end{array}$ & $\begin{array}{l}\text { Kads } \\
\mathrm{L} / \mathrm{g}\end{array}$ \\
\hline 10 & & 0.952 & -28.713 & 1983 \\
\hline 20 & & 0.957 & -27.282 & 1112 \\
\hline 30 & 298 & 0.958 & -26.340 & 760 \\
\hline 40 & & 0.961 & -25.821 & 616 \\
\hline 50 & & 0.962 & -25.334 & 506 \\
\hline
\end{tabular}

The high values of $\mathrm{K}_{\text {ads }}$ mean good inhibition efficiency of the inhibitor and strong electrical interaction between the absorber and the adsorbent. The negative values of $\Delta G^{\circ}$ ads indicate that the adsorption of inhibitor molecule on steel surface is spontaneous and also the strong interaction between inhibitor molecules and the metal surface 37). Generally, an adsorption process suggests either physisorption or chemisorption. $\Delta \mathrm{G}^{\circ}$ ads value lower than $(-40 \mathrm{~kJ} / \mathrm{mol})$ are related to the chemisorption between charged molecule and charged metal $\stackrel{(38-39)}{ }$. In the present work, the value of $\Delta \mathrm{G}^{\circ}$ ads is found to be lower than $(-40 \mathrm{~kJ} / \mathrm{mol})$; means that the adsorption mechanism of BHMET on carbon steel surface is mainly the chemisorption.

\section{Thermal analysis study of BHMET}

Thermal analysis curve TGA \& DTA was shown in Fig. 8 and table (5). The inhibitor (BHMET) was stable thermally up to a temperature $\left(220{ }^{\circ} \mathrm{C}\right)$, and also the $\left(\mathrm{T}_{\max }\right)$ (temperature of decomposition) was (345 $\left.{ }^{\circ} \mathrm{C}\right)$ which is indicate that the inhibitor was stable, and the char residue at $\left(600{ }^{\circ} \mathrm{C}\right)$ was $7 \%$. The initial decomposition temperature of inhibitor $\left(T_{i}=230\right.$ $\left.{ }^{\circ} \mathrm{C}\right)$ and the final decomposition temperature was $\left(\mathrm{T}_{\mathrm{f}}\right.$ $\left.=400{ }^{\circ} \mathrm{C}\right)$. From Fig. 8 the DTA curve indicate that decomposition of the inhibitor was Endothermic. ${ }^{(41)}$

Table 5. Thermal analysis TGA and DTA parameters of BHMET

\begin{tabular}{ll} 
Decomposition temperature $\left(\mathrm{T}_{\max }\right)$ & $345{ }^{\circ} \mathrm{C}$ \\
Rate of Decomposition $\% / \mathrm{min}$ & $3.30{ }^{\circ} \mathrm{C}$ \\
$50 \%$ wt. loss $\left(\mathrm{T}_{1 / 2}\right)$ & $315{ }^{\circ} \mathrm{C}$ \\
Char yield $7 \%$ at & $600{ }^{\circ} \mathrm{C}$ \\
$\Delta \mathrm{T}=\mathrm{T}_{\mathrm{f}}-\mathrm{T}_{\mathrm{i}}=(400-230){ }^{\circ} \mathrm{C}$ & $170{ }^{\circ} \mathrm{C}$ \\
\hline
\end{tabular}

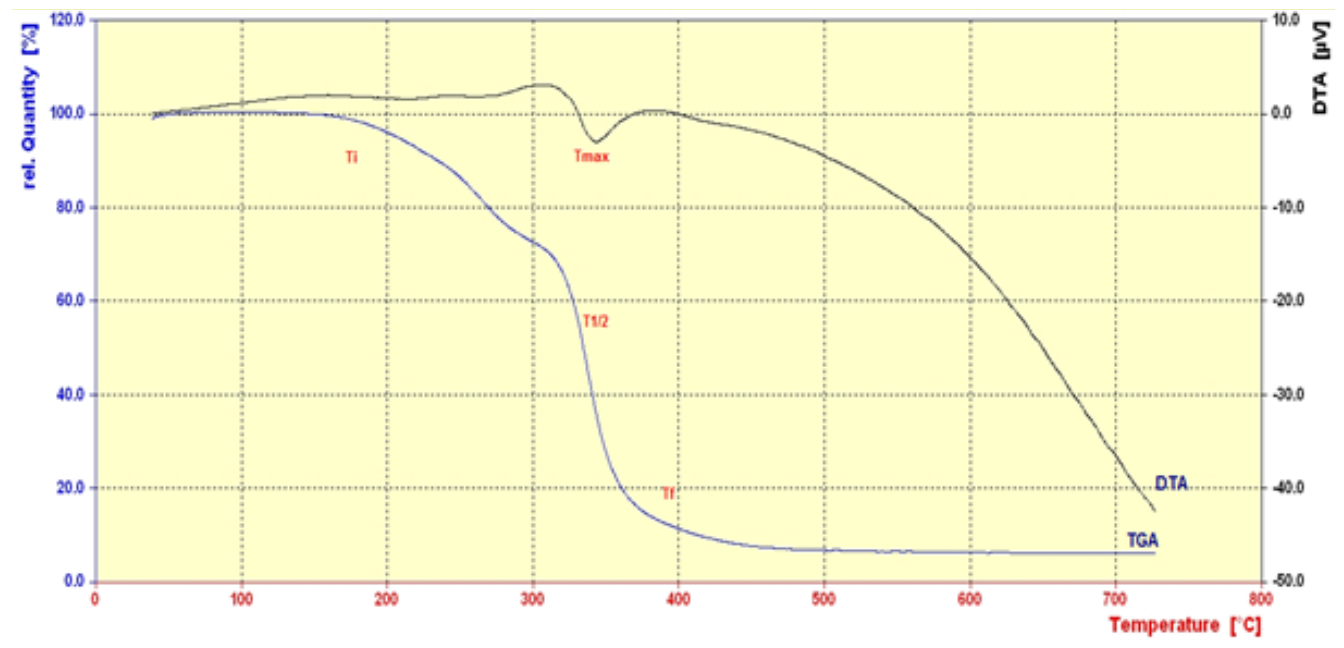

Figure 8. Thermal analysis, TGA and DTA curve of BHMET 


\section{CONCLUSIONS}

Bis[2-\{(6-Mono malic acid -hydroxyethyl ester $\}$ sulfanyl] ethyl terephthalate (BHMET) prepared and used as corrosion inhibitors of carbon steel in $0.1 \mathrm{M}$ $\mathrm{HCl}$ solution. Two parameters effect was studied, The concentration of the inhibitor (BHMET) and the temperature. From the data the higher (\%IE) was for the $10 \mathrm{ppm}$ at 298 and at 313 the $10 \mathrm{ppm}$ was

the higher inhibitor efficiency. The adsorption of the BHMET inhibitor onto the surface of the carbon steel follows the Langmuir's adsorption isotherm. The prepared compound was mixed type inhibitor and the $\Delta \mathrm{G}^{\circ}{ }_{\text {ads }}$ indicates that the adsorption of (BHMET) inhibitor involves chemisorption.

\section{REFERENCES}

1. Colomines $G$, Robin J, Tersac G, Study of the Glycolysis of PET by Oligoesters. Polymer.2005;46: 3230-3247. https://doi.org/10.1016/j.polymer.2005.02.047

2. Achilias D S, Roupakias C, Megalokonomos P, Lappas A A, Antonakou E V. Chemical recycling of plastic wastes made from polyethylene (LDPE and HDPE) and polypropylene (PP). J Hazard Mater. 2007; 149 : 536-542. https://doi.org/10.1016/j.jhazmat.2007.06.076

3. Achilias D S, Chemical Recycling of Poly(Methyl Methacrylate) by Pyrolysis. Potential use of the Liquid Fraction as a Raw Material for the Reproduction of the Polymer. European Polymer Journal.2007;43(6):2564-2575.

https://doi.org/10.1016/j.eurpolymj.2007.02.044

4. Al-Salem S M , Lettieri P , Baeyens J , Recycling and Recovery Routes of Plastic Solid Waste (PSW). A Review. Waste Management.2009; 29: 2625-2643.

https://doi.org/10.1016/j.wasman.2009.06.004

5. Chilton T, Burnley S, Nesaratnam S, A Life Cycle Assessment of the Closed-Loop Recycling and Thermal Recovery of Post-Consumer PET. Resources, Conservation and Recycling.2010; 54:1241-1249.

https://doi.org/10.1016/i.resconrec.2010.04.002
6. Dullius J, Ruecker C, Oliveira V, Ligabue R, Einloft S. Chemical recycling of post-consumer PET: Alkyd resins synthesis. Progress in Organic Coatings.2006;57:123-127.

https://doi.org/10.1016/j.porgcoat.2006.07.004

7. Hamad K, Kaseem M, Deri F. Recycling of waste from polymer materials: An overview of the recent Works. Polymer Degradation and Stability.2013; 98: 2801-2812.

https://doi.org/10.1016/j.polymdegrad$\underline{\text { stab.2013.09.025 }}$

8. Achilias D, Tsintzou G, Nikolaidis A, Bikiaris D, Karayannidis G. Aminolytic depolymerization of poly(ethylene terephthalate) waste in a microwave reactor. Polym Int. 2011;60: 500-506.

https://doi.org/10.1002/pi.2976

9. Valipour M ,Shekarchi M ,Ghods P, Comparative studies of experimental and numerical techniques in measurement of corrosion rate and time-to-corrosion-initiation of rebar in concrete in marine environments. Cement \& Concrete Composites.2014;48: 98- 107.

https://doi.org/10.1016/j.cemconcomp.2013.11.001

10. Kim J, Park S R, Moon I, Development of a new automatic system for fault tree analysis for chemical process industries. Korean Journal of Chemical Engineering,2009;27: 1839-1844.

11. Al-Sherrawi M ,Lyashenko V, Edaan E ,Sotnik I , Corrosion of Metal Construction Structures. International Journal of Civil Engineering and Technology.2018; 9(6):437446.

12. Alvarez-Pampliega A and et al, Corrosion Study on Al-Rich Metal-Coated Steel by odd Random Phasemultisine Electrochemical Impedance Spectroscopy.Electrochimica Acta.2014;124:165-175.

https://doi.org/10.1016/j.electacta.2013.09.159

13. Juhaiman L, Polyvinyl pyrrolidone as a Corrosion Inhibitor for Carbon Steel in HCl. Int. J. Electrochem. Sci.2016; 11:2247 - 2262.

14. Yasir A, Khalaf A, Khalaf M, Preparation and Characterization of Oligomer from Recycled PET and Evaluated as a Corrosion Inhibitor for C-Steel Material in $0.1 \mathrm{M} \mathrm{HCl}$,Open Journal of 
Organic Polymer Materials.2017; 7:1- 15. https://doi.org/10.4236/ojopm.2017.71001

15. Khalaf M ,Al-Mowali A , Adam G, Rheological studies of modified maleated polyethylene/ medium density polyethylene blends,Malaysian Polymer Journal.2008; 3(2): 54-64.

16. Silverstien M, Webster F X, Kiemle D J. Spectrometric Identification of Organic Compounds. 2005, John Wiley \& Sons, Inc., New York.

17. Gauglitz G, Vo-Dinh V, Handbook of Spectroscopy, 2003, WILEY-VCH Verlag GmbH \& Co.). https://doi.org/10.1002/3527602305

18. Mistry B , Handbook of Spectroscopic Data Chemistry,2009, Oxford Book Company.

19. Shukla K, Quraishi M , Cefotaxime sodium: a new and efficient corrosion inhibitor for mild steel in hydrochloric acid solution, Corros. Sci.2009;51:1007-1011.

https://doi.org/10.1016/j.corsci.2009.02.024

20. Singh A , Singh A, Ebenso E, Inhibition Effect of Cefradine on Corrosion of Mild Steel in $\mathrm{HCl}$ Solution, Int. J. Electrochem. Sci.2014; 9: $352-$ 346.

21. Quraishi M, Shukla K, Inhibitive Effect of Imidazolium Based Aprotic Ionic Liquids on Mild Steel Corrosion in Hydrochloric Acid Medium , Mater. Chem. Phys.,2004 ; 85: 420.

22. Uhlig H, Corrosion and Corrosion Control,1971, 2nd Ed., John Wiley and sons Inc.

23. Alexander M G, Beushausen H, Dehn F , Moyo P. Concrete Repair, Rehabilitation and Retrofitting II, 2008, CRC Press. https://doi.org/10.1201/9781439828403

24. Zerga B , and et al, Substitution Effect of two Oxygen Atoms by Sulphur Atoms in New Synthesized Benzodiazepine Molecules towards Mild Steel Corrosion Inhibition in Hydrochloric Acid, Int. J. Electrochem. Sci., 2014; 7(10):1019010204.

25. Shalabi K, Abdallah Y, Hassan H, Fouda A, Adsorption and Corrosion Inhibition of Atropa Belladonna Extract on Carbon Steel in $1 \mathrm{M} \mathrm{HCl}$ Solution, Int. J. Electrochem. Sci., 2014,9 14681487.

26. Bhat J, Alva V, Corrosion inhibition of aluminium by 2-chloroictinic acid in $\mathrm{HCl}$ meduim, Indian Journal of Chemical Technology, 2009; 16: 228-233.
27. Solmaz R , Kardas G, Yazıc1 B , Erbil M , Adsorption and corrosion inhibitive properties of 2-amino-5-mercapto-1,3,4-thiadiazole on mild steel in hydrochloric acid media,Colloids Surf. A Physicochem, Eng.Aspects,2009 ;312(1) :7-17. https://doi.org/10.1016/j.colsurfa.2007.06.035

28. Tao $Z$ and et al, A study of differential polarization curves and thermodynamic properties for mild steel in acidic solution with nitrophenyltriazole derivative, Corros. Sci.,2012; 60: 205-213. https://doi.org/10.1016/j.corsci.2012.03.035

29. Ahamad I, Prasad R, Quraishi M, Adsorption and inhibitive properties of some new Mannich bases of Isatin derivatives on corrosion of mild steel in acidic media, Corrosion Science, 2010; 52 (4): 1472-1481.

https://doi.org/10.1016/j.corsci.2010.01.015

30. Hackerman N, Recent Advances in Understanding Of Organic Inhibitors, Corrosion, 1962;18(9):332t-337t.

https://doi.org/10.5006/0010-9312-18.9.332

31. Ateya B , El-Anadouli B , El-Nizamy F, The effect of thiourea on the corrosion kinetics of mild steel in $\mathrm{H}_{2} \mathrm{SO}_{4}$, Corros.Sci.,1984; 24: 497507.

https://doi.org/10.1016/0010-938X(84)90032-5

32. Babic-Samardzija $\mathrm{K}$ and et al, Inhibitive Properties and Surface Morphology of a Group of Heterocyclic Diazoles as Inhibitors for Acidic Iron Corrosion, Langmuir, 2005 ;21:12187-12196.

https://doi.org/10.1021/la0517661

33. Bouayed M and et al, Experimental and theoretical study of organic corrosion inhibitors on iron in acidic médium, Corros. Sci.,1998;41(3):501517.

https://doi.org/10.1016/S0010-938X(98)00133-4

34. Mansfeld F, Kending M , Tsai S, Corrosion kinetics in low conductivity media-I. Iron in natural waters, Corrosion, 1982; 22(5): 455-471.

https://doi.org/10.1016/0010-938X(82)90021-X

35. Benali O, Larabi L, Tabti B, Harek Y, Influence of 1-methyl 2-mercapto imidazole on corrosion inhibition of carbon steel in $0.5 \mathrm{M} \mathrm{H}_{2} \mathrm{SO}_{4}$, Anti-Corros. Met. Mat., 2005; 52 : 280-285.

https://doi.org/10.1108/00035590510615776

36. Benali O,Larabi L, Mekelleche M, Harek Y, Influence of substitution of phenyl group by naphth$y l$ in a diphenylthiourea molecule on corrosion 
inhibition of cold-rolled steel in $0.5 \mathrm{M} \mathrm{H}_{2} \mathrm{SO}_{4}$, J. Mater. Sci.,2006; 41(21): 7064-7073.

https://doi.org/10.1007/s10853-006-0942-6

37. Talati J, Gandhi D, N-heterocyclic compounds as corrosion inhibitors for aluminium-copper alloy in hydrochloric acid,Corros. Sci.,1983; 23(12):1315-1332.

https://doi.org/10.1016/0010-938X(83)90081-1

38. Brycki, B. and et al, Organic Corrosion Inhibitors. Corrosion Inhibitors, Principles and Recent Applications, 2018 Publish by Intech. https://doi.org/10.5772/intechopen.72943
39. Brylee D B, Tiu R C A. Polymeric corrosion inhibitors for the oil and gas industry: Design principles and mechanism, Reactive and Functional Polymers, 2015; 95: 25-45.

https://doi.org/10.1016/j.reactfunctpolym.2015.08.006

40. Bouklah M. and et al. Thermodynamic characterisation of steel corrosion and inhibitor adsorption of pyridazine compounds in $0.5 \mathrm{M} \mathrm{H} 2 \mathrm{SO} 4$, Letters, 2006; 60(15):1901-1905.

https://doi.org/10.1016/i.matlet.2005.12.051

41. Groenewoud W, Characterisation of Polymers by Thermal Analysis,2005, first edition, Elsevier, Netherlands. 